\title{
Container Baby Syndrome
}

\author{
B Anitha
}

\begin{abstract}
In recent years, there is a rapid increasing incidence of developmental delays in normal infants. These developmental delays may be caused by modern child rearing practices. Nowaday's newborn babies or young infants are placed in a container or carriers in terms of stroller, baby supportive devices, etc., for a long period of time which may cause less opportunity for the child to lie on their tummy leading to container baby syndrome (CBS). CBS is otherwise known as bucket baby syndrome. This condition may impact normal growth and development of a newborn which leads to problems in normal physical, cognitive and social interactive behaviors and physical deformities. Thus it is very fundamental requisite for the family members, caregivers and healthcare personnel to recognize the symptoms of CBS to alleviate the difficulties and restore the normal movement and ensure the optimal growth and development of the child.

Keywords: Bucket baby syndrome, Container baby syndrome, Developmental delay.

Pondicherry Journal of Nursing (2019): 10.5005/jp-journals-10084-12103
\end{abstract}

\section{INTRODUCTION}

Container baby syndrome is a significant problem that is emerging in recent years, and many babies are having skull and facial deformities, muscle spasm, difficulties in speech, vision, hearing and thinking abilities and even obesity. ${ }^{1}$ Babies are needed to move, explore, inquire into and learn regarding their own environment. When they are in a container most of the time a day, the babies could not learn to adapt to the environment. Modern parents can take precautions which help avoid potential consequences of their babies. ${ }^{2}$

\section{Definition}

Container baby syndrome is a collection of movement, behavior, and other cognitive issues as result of a consuming considerable amounts of time in various containers with minimal opportunities for tummy time. They are contained in a small space and essentially immobilized while resting on the back of their heads (Figs 1 to 3 ). ${ }^{3}$

\section{Commonly Used Containers}

- Car seats

- Strollers

- Bamboo seats

- Bouncy swings

- Rockers

- Bouncer seats

- Nursing cushions

- Vibrating chairs

- Jumpers

- Exersaucers

- Activity gyms/centers

- Walkers

- High chain ${ }^{4}$

\section{What Does CbS Cause?}

Spending longer time in a container per day can cause developmental issues, ${ }^{8}$ such as:

- Flat head syndrome: ${ }^{4}$ The back or the side of the skull is abnormally flat (Fig. 4).
Department of Obstetrics and Gynecology Nursing, Kasturba Gandhi Nursing College, Sri Balaji Vidyapeeth, Puducherry, India

Corresponding Author: B Anitha, Department of Obstetrics and Gynecology Nursing, Kasturba Gandhi Nursing College, Sri Balaji Vidyapeeth, Puducherry, India, Phone: +91 9566669061, e-mail: sribalani86@gmail.com

How to cite this article: Anitha B. Container Baby Syndrome. Pon J Nurs 2019;12(1):21-24.

Source of support: Nil

Conflicts of interest: None

- Asymmetrical facial features: The face of the baby may appear unequal as a result of flat head syndrome and/or skull deformities. ${ }^{7}$

- Torticollis: Difficulty in turning the head of the baby to one side, neck rigidity, muscle tightness (Fig. 5).,

- Delayed development includes motor, sensory, cognition, communication, social, emotional $^{6}$

- Otitis media

- Behavioral problems

- Limited movement, poor muscle strength and its coordination. ${ }^{14}$

- Speech, sight, hearing, and thinking issues

- Attention deficit hyperactivity disorder (ADHD) ${ }^{14}$

- Increased weight/obesity ${ }^{3}$

- Injury or death. ${ }^{19}$

\section{How it Can be Recognized?}

Child's parents, family members, or healthcare givers are the key persons to recognize that the baby is having limited movement in turning its head or body, problems in hearing and vision, mal position of the head or neck i.e., tilting of the head to one side, etc.

\section{History Taking}

Collection of baby's health history about the daily activity of the baby and handling techniques each day, and gently evaluate the symptoms of CBS such as:

- Delayed in growth and development: The baby may show difficulty in crawling rolling, turning, sitting and standing, etc. ${ }^{10}$

o The Author(s). 2019 Open Access This article is distributed under the terms of the Creative Commons Attribution 4.0 International License (https://creativecommons. org/licenses/by-nc/4.0/), which permits unrestricted use, distribution, and non-commercial reproduction in any medium, provided you give appropriate credit to the original author(s) and the source, provide a link to the Creative Commons license, and indicate if changes were made. The Creative Commons Public Domain Dedication waiver (http://creativecommons.org/publicdomain/zero/1.0/) applies to the data made available in this article, unless otherwise stated. 


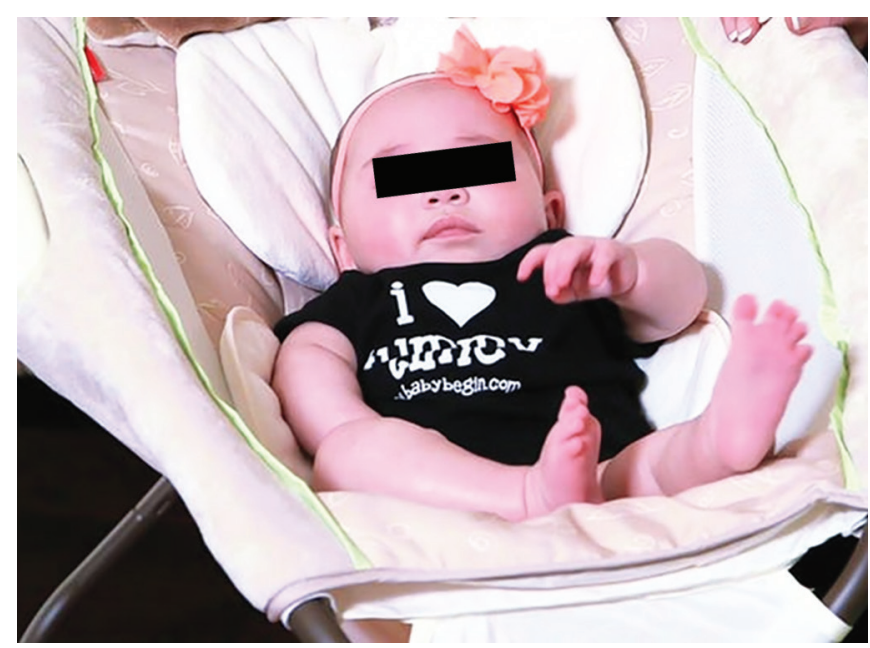

Fig. 1: Baby in a container (lying on back)

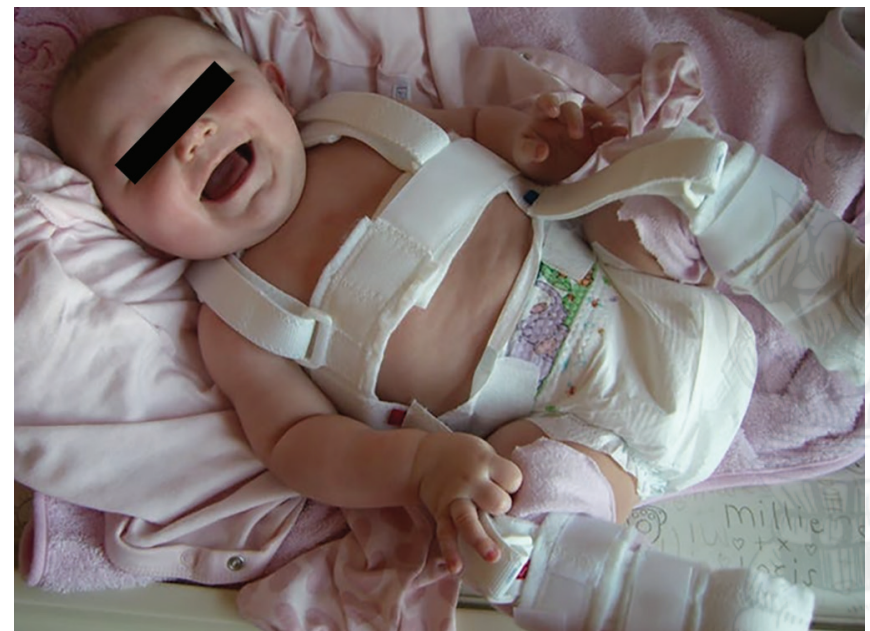

Fig. 3: Baby in a restraint

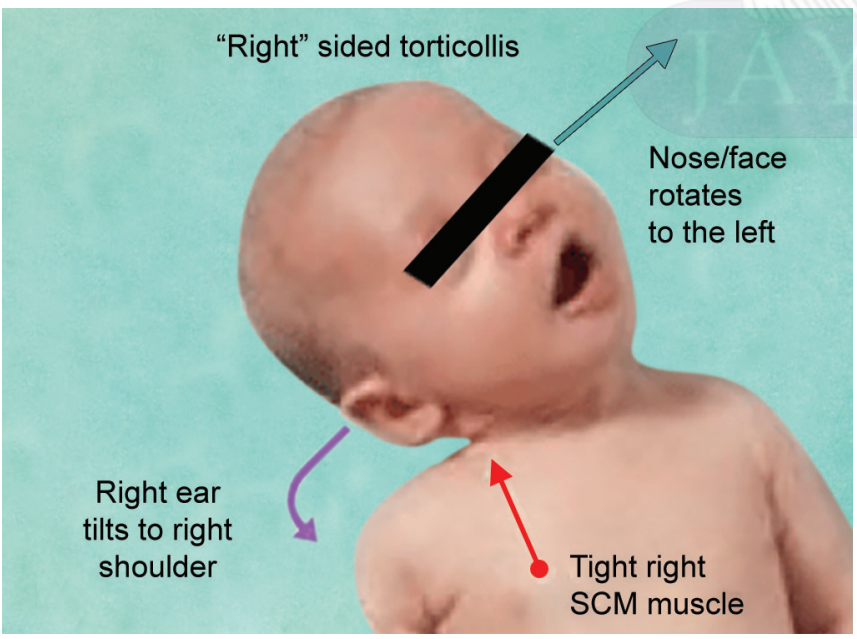

Fig. 5: Torticollis

- Vision or hearing issues: The baby may express delay in the development of hearing or vision skills, such as problems in following moving objects or lacking in obey the commands, etc. $^{10,11}$

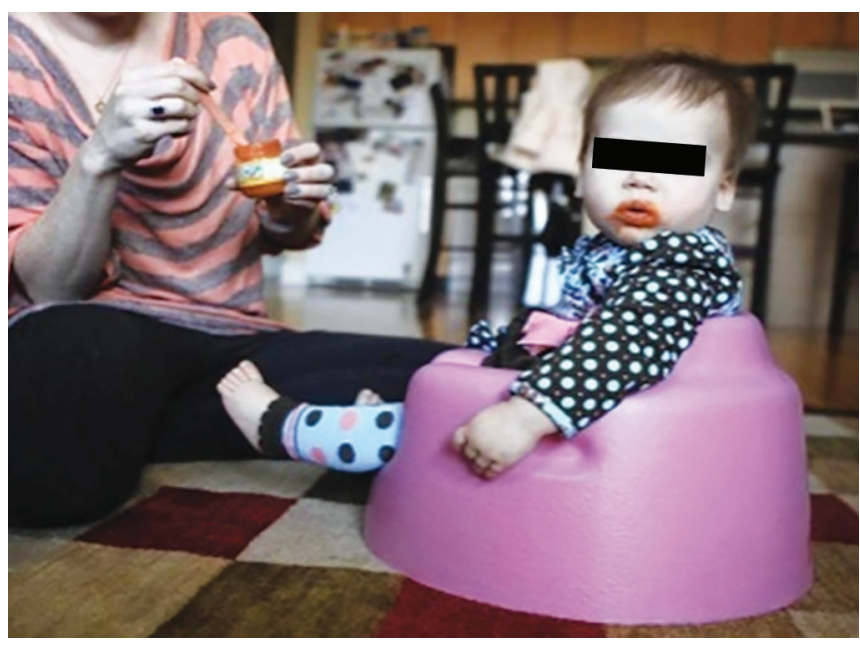

Fig. 2: Baby in a container (sitting position)
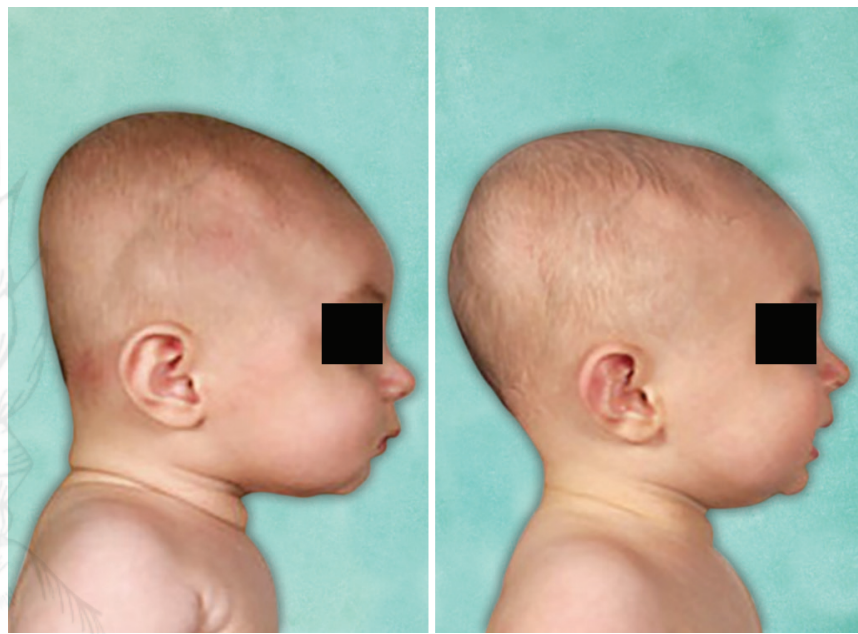

Fig. 4: Flat head syndrome

- Delayed development in baby's thinking abilities: The baby may experience delayed development in problem-solving skills, in adopting or understanding their surroundings, and delayed language skills. ${ }^{13}$

\section{Physical Examination}

- The shape of the skull and face and how does the baby hold the head and neck

- The baby's muscle development

- The movement of baby's head, body, and limbs

- Activity of the baby's head and limbs when lying on the tummy

- How well the baby can roll over, crawl, and change body positions

- How well the baby can track objects with the eyes ${ }^{18}$

\section{Can this Condition be Prevented?}

Container baby syndrome is preventable with early identifying the problems and gently handling technique of the baby (Fig. 6). ${ }^{20}$ Guidelines for Preventing CBS

- Limit the baby's time in a closed carrier or containers, such as chairs with restriction and strollers; it has to be utilized only when the baby is actually need to be transported to somewhere else. ${ }^{11}$ 


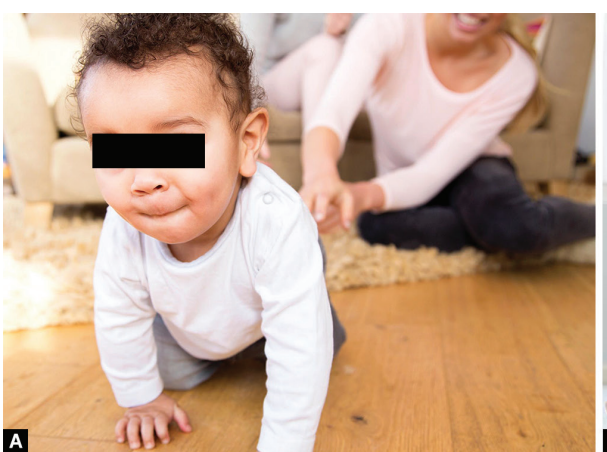

Fig. 6: Identifying problems in (A) crawlings; (B) kneeling

- Increase the time for the baby lying on baby's tummy when baby is awake (with constant supervision).

- Hold the baby in the arms or a sling for short periods and allow the baby to expose the environment throughout the day which aids to ensure the natural adaptation to the surroundings.

- Let the baby play freely in a play pen.

- Allow the baby to play and crawl on a mat, blanket on the floor, on the tummy or the back.

- Feeding to be ensured in arms initially, then in high chair after 4-6 months.

- Sleep practice of the baby should be encouraged in crib/ bassinette/pack. ${ }^{11,23}$

\section{How this CBS can be treated? Repositioning}

- Floor time with active play with adults

- Back to sleep-alternating ends of the crib

- Carry baby - varying how you carry baby

- Sitting on lap (horsey style) with support at hips/trunk.

\section{Helmet}

Helmet therapy may use for infant with flat head syndrome. ${ }^{6}$

\section{Physical Therapy}

Physical therapy need to be initiated and followed early to the baby and help a child to regain their strength and motivating their physical and psychological well being. ${ }^{12,14}$

\section{Surgery if Needed}

In case of torticollis: for a child older than 12 months with persistent sternocleidomastoid contracture limiting head movement. ${ }^{7,17}$

\section{Role of a Nurse in Preventing and Treating Container Baby Syndrome} Improve the Optimal Physical Movement, Skills and Physical Strength

Nurse should encourage the baby to learn new movements, make them to strength their underdeveloped muscles. They can utilize the appropriate toys, games with music to enable the child to engage with learning environment.

\section{Positioning}

The nurse and healthcare personnel will teach the parents where to reposition the baby and assist them in developing normal physical

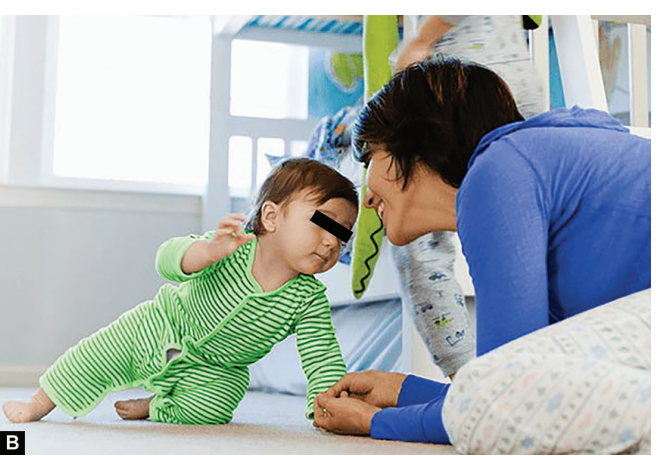

movements, building the strength, and support the head to ensure the regaining to its normal skull shape. ${ }^{15}$ The preventive and curative measures involves allowing the infant for being on its tummy on the floor with supervision and do not place the child to sleep in a carrier or container at night. ${ }^{18}$

\section{Parent Education}

Education will help the parents or care giver to learn about the safely place, position for the baby on its tummy for a longer period whenever the baby is awake. Teach the parents and care givers to handle the baby and explore to the natural atmosphere for their optimal growth and development of the child. ${ }^{22}$

\section{Recommended Modalities}

Based on each child's condition, The nurse may recommend for prescribed physical therapy with different modalities, such as protective head gear, to aid for positive outcome in physical and cognitive abilities of the child. ${ }^{1,7}$ And also assist them in treating the mal position and deformities. ${ }^{21}$

\section{Conclusion}

Parents might think the containers protect their babies from accidents. But it restricts to wiggle, squirm or move. This practice causes lack of skill in turning around, crawling, kneeling and standing. ${ }^{14}$ CBS does not occur due to medical or neurological/ orthopedic pathological issues. It occurs only because of the poor child rearing practices. With appropriate handling techniques of the baby, the signs and symptoms of CBS can be minimized. Babies must learn on their own by exploring to their own environment and learn to crawl, sit, and stand on their own. They will prefer the positions which naturally adopt the external environment. $^{9}$

\section{References}

1. Persing J, James H, Swanson J, Kattwinkel J. Prevention and management of positional skull deformities-Container baby syndrome. Pediatrics 2003;112:199-202. DOI: 10.1542/peds.112.1.199.

2. Alexandria VA. Lack of tummy time leads to motor delays in infants. Novemeber 28, 2018.

3. https://www.mom.com/container-baby-syndrome-10things.

4. http://www.babyzeen.com/newborn-safety.

5. Erynn R. Things that cause Container Baby Syndrome. Baby Gaga. November 2017.

6. Whiteman H. Helmet therapy for Infant positional skull deformation'should be discouraged'. May 2014. 
7. Saxena AK. Pediatric Torticollis Surgery Treatment \& Management. March 08, 2019.

8. Coulter-O'Berry C, Lima D. Tummy time: tips for parents. MoveForwardPT.com. Accessed November 28, 2018.

9. Van Wijk RM, Pelsma M, Groothuis-Oudshoorn CG, IJzerman MJ, van Vlimmeren LA, Boere-Boonekamp MM. Response to pediatric physical therapy in infants with positional preference and skull deformation. Phys Ther 2014;94(9):1262-1271. DOI: 10.2522/ptj. 20130304.

10. McCullough A. Diagnosing flat head syndrome. Primary Health Care 2013;23(5):24-25. DOI: 10.7748/phc2013.06.23.5.24.e723.

11. Flannery AB, Looman WS, Kemper K. Evidence-based care of the child with deformational plagiocephaly, part II: management. J Pediatr Health Care 2012;26(5):320-331. DOI: 10.1016/j.pedhc.2011. 10.002 .

12. Persing J, James $H$, Swanson J, Kattwinkel J. Prevention and management of positional skull deformities in infants: American Academy of Pediatrics Committee on Practice and Ambulatory Medicine, Section on Plastic Surgery, and Section on Neurological Surgery. Pediatrics 2003;112(1 Pt 1):199-202. DOI: 10.1542/ peds.112.1.199.

13. Hunziker $U$, Barr R. Increased carrying reduces infant crying: a randomized controlled trial. Pediatrics 1983;77:641-648.

14. Lasher D. Container Baby Syndrme. What it is \& how to prevent it. Nov. 29, 2018.

15. Follert J. Beware 'container baby' syndrome: Babies need tummy time, free movement. Retrieved from http://www.durhamregion. com/community-story/5789094-beware-container-baby-syndromedurham-expert-says-babies-need-tummy-time-free-movement. August 11, 2015.

16. Kaplan SL, Coulter C, Sargent B. Physical therapy management of congenital muscular torticollis: evidence-based clinical practice guideline from the APTA academy of pediatric physical therapy. Pediatr Phys Ther 2018;30:240-290. DOI: 10.1097/ PEP.0000000000000544.

17. American Physical Therapy Association, Move forward Guide. Physical Therapist's Guide to Container BabySyndrome. https://www. moveforwardpt.com/SymptomsConditionsDetail.aspx?cid=53d902641846-4b86-891f-0facc63db3e8. December 102018.

18. Sims A, Chounthirath T, Yang J, Hodges NL, Smith GA. Infant WalkerRelated /Injuries in the United States. Pediatrics 2018;142(4): pii: e20174332. DOI: 10.1542/peds.2017-4332.

19. Siegel AC, Burton RV. Effects of baby walkers on motor and mental development in human infants. J Dev Behav Pediatr 1999;20:355. DOI: 10.1097/00004703-199910000-00010.

20. Abbot AL, Bartlett DJ. Infant motor development and equipment use in the home. Child Care Health Dev 2001;27:295-306. DOI: 10.1046/j.1365-2214.2001.00186.x.

21. Tamara. Daily Parenting tips. Container Baby Syndrome \& its prevention. March 19, 2019.

22. Shabangu S. Aimee Erb.Jirovec. Child Bearing Practices. July 13, 2016.

23. Ramirez K. Signs \& Symptoms of Container Baby Syndrome. March 27, 2019. 